\title{
Towards a cross-border exposure model for the Earthquake Model Central Asia
}

\author{
Marc Wieland ${ }^{1,{ }^{\star}}$, Massimiliano Pittore ${ }^{1}$, Stefano Parolai ${ }^{1}$, Ulugbek Begaliev², \\ Pulat Yasunov $^{3}$, Jafar Niyazov ${ }^{3}$, Sergey Tyagunov ${ }^{1}$, Bolot Moldobekov ${ }^{4}$, Saidislom Saidiy ${ }^{5}$, \\ Indalip Ilyasov ${ }^{6}$, Tanatkan Abakanov ${ }^{7}$
}

${ }^{1}$ Helmholtz Center Potsdam - German Research Center for Geosciences, Potsdam, Germany

${ }^{2}$ International University of Innovation Technologies, Bishkek, Kyrgyzstan

${ }^{3}$ Institute of Geology, Earthquake Engineering and Seismology, Academy of Sciences of the Republic of Tajikistan, Dushanbe, Tajikistan

${ }^{4}$ Central Asian Institute for Applied Geosciences, Bishkek, Kyrgyzstan

${ }^{5}$ Tashkent Architectural Building Institute, Tashkent, Uzbekistan

${ }^{6}$ Research Institute for Seismic Resistant Construction, Ashgabat, Turkmenistan

${ }^{7}$ Institute of Seismology, Academy of Sciences of the Republic of Kazakhstan, Almaty, Kazakhstan

\section{Article history}

Received September 17, 2014; accepted January 15, 2015.

Subject classification:

Seismic Risk, Surveys, measurements and monitoring, Satellite geodesy, General or miscellaneous, Instruments and techniques.

\begin{abstract}
This work provides an insight into the development of the first harmonized exposure model for Central Asia. The model was derived in the frame of the Earthquake Model Central Asia (EMCA) project, which is the regional initiative for Central Asia to the Global Earthquake Model (GEM). The EMCA exposure model combines commonly used data sources and acquisition techniques (e.g., rapid visual screening) with novel rapid assessment approaches (e.g., satellite remote sensing and omnidirectional imaging) in the framework of an integrated sampling scheme and stores the data in a multi-resolution spatio-temporal database. The exposure model implements a newly developed building typology, harmonized for the five Central Asian countries (Kazakhstan, Kyrgyzstan, Tajikistan, Turkmenistan and Uzbekistan) and follows the international building taxonomy of the GEM. Emphasis is given to the multi-scale nature and the temporal dynamics of exposure data. Results from a selected urban area are provided to illustrate the current state of the continuously updated exposure model.
\end{abstract}

\section{Introduction}

Central Asia, covering the countries of Kazakhstan, Kyrgyzstan, Tajikistan, Turkmenistan and Uzbekistan (Figure 1) with a combined population of about 60 million people is one of the seismically most hazardous regions of the world. A high level of seismic hazard [Giardini et al. 1999, Ullah et al. 2015a (this issue)] coupled with a potentially high physical vulnerability of the building stock results in a high seismic risk for the region. This has also been highlighted by a workshop held in Almaty in October 1996 on the "Strategies for urban earthquake risk management for the Central Asian Republics" where it was pointed out that the seismic resistance of Soviet-era buildings was significantly lower than was officially declared [King et al. 1999].

As a heritage of the common Soviet history of Central Asia, the different countries share a largely similar set of building types and construction practices. After the collapse of the Soviet Union, however, the classification and characterization of the building stock developed independently in the countries, resulting in significantly different building typologies as manifested in the respective national building codes. Where there seems to be a good knowledge about the composition of governmental buildings that were constructed during the Soviet-era, information about the building stock of the private sector that mainly developed after 1990 is largely missing in exposure and vulnerability models. Moreover, due to a general lack of resources to keep track of the increasingly high spatio-temporal evolution of urban areas, only sparse data are available about exposed assets. The available data are, moreover, often outdated, spatially fragmented or highly aggregated and their characterization appears 


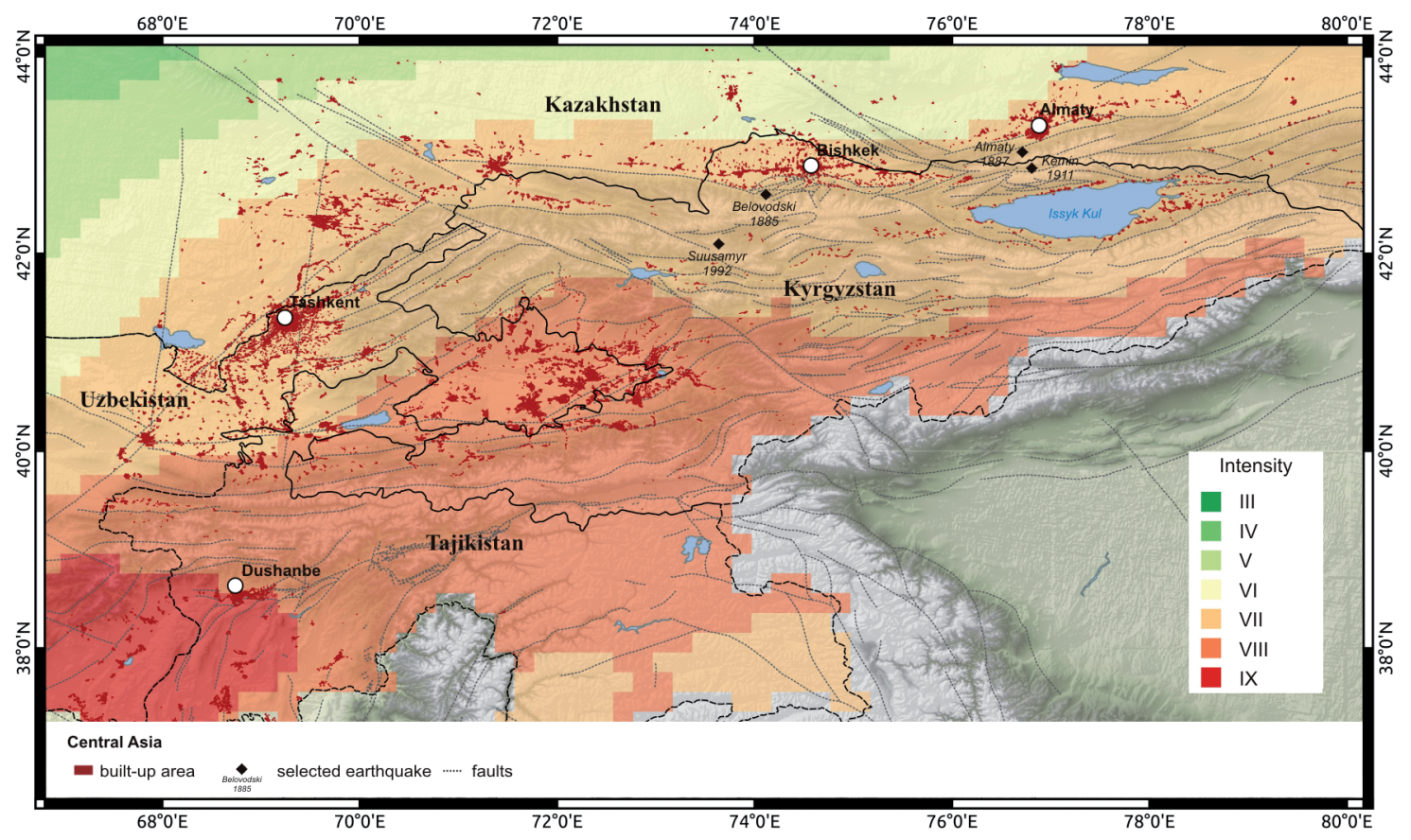

Figure 1. The study area of Central Asia with settlement extents extracted from satellite images, locations of major earthquakes and seismic hazard from a smoothed seismicity approach.

to be strongly heterogeneous across national borders.

Within the Earthquake Model Central Asia (EMCA), available datasets are being collected and harmonized in terms of their spatial and attribute characterization. Moreover, new tools and techniques to estimate exposure in a rapid, standardized and comparable way are being developed in order to capture missing data for the region. These tools shall be able to cope with the increasingly high spatio-temporal variability of the exposed assets and provide a spatial definition of the exposure model that is comparable with what can be achieve from a hazard assessment both on a regional and local scale [Ullah et al. 2015b (this issue)].

The aim of this paper is to describe the development of a cross-border exposure model for the EMCA, including the collection and harmonization of available data and the development of tools and methods to continuously update the exposure model at multiple spatial scales. The following section provides a brief summary of the methods deployed and developed within the EMCA for exposure assessment and highlights how they were combined within a multi-scale approach. In Section 3 results are shown at different analysis levels for Central Asia as a whole and for a selected urban area in particular. The paper finishes with a discussion and conclusions in Section 4.

\section{Methods}

The approach followed in this study for the assessment of exposed assets combines different data sources and acquisition techniques in the framework of an integrated sampling scheme, where each source and technique is used to infer specific scale-dependent information about an exposed building stock and its population [Wieland et al. 2012a]. Top-down are combined with bottom-up assessments and three analysis levels with respective spatial scales are distinguished, which will be referred to as L1 (regional scale), L2 (neighborhood scale) and L3 (per-building scale).

\subsection{EMCA building typology and L1 exposure estima-} tion at regional scale

At L1 global geospatial datasets are combined with local expert knowledge to identify and locate exposed settlements, to develop a unified building taxonomy for the region and to derive composite models of building types for urban and rural areas of the different countries. This regional scale represents a first level approximation of exposure over large areas, ranging from settlement to district or country-wide aggregation.

Within EMCA, the national building typologies were carefully reviewed and a limited set of building types that are representative for the region was agreed upon amongst experts on building construction from all Central Asian countries. The resulting EMCA building typology consists of 6 main building types with a total of 16 subtypes (Table 1). Look-up tables link the EMCA building types to the building types in the respective national building codes to guarantee transparency and allow for forward and backward transformation between the typologies. Detailed building reports have been compiled for each EMCA building type and subtype with a standardized characterization of structural attributes following the GEM Building Taxonomy. More 


\begin{tabular}{|c|c|c|c|c|}
\hline $\begin{array}{l}\text { EMCA } \\
\text { type }\end{array}$ & subtype & $\begin{array}{l}\text { Building } \\
\text { class }\end{array}$ & $\begin{array}{l}\text { Building } \\
\text { subclass }\end{array}$ & $\begin{array}{l}\text { Country } \\
\text { code }\end{array}$ \\
\hline \multirow[t]{6}{*}{ EMCA-1 } & 1,1 & $\begin{array}{l}\text { load bearing } \\
\text { masonry wall buildings }\end{array}$ & $\begin{array}{c}\text { unreinforced masonry-buildings with walls of brick masonry, } \\
\text { stone, or blocks in cement or mixed mortar (no seismic design) - } \\
\text { wooden floors. 2-4 stories. }\end{array}$ & KY-1.4 \\
\hline & \multirow[t]{2}{*}{1,2} & & $\begin{array}{l}\text { unreinforced masonry-buildings with walls of brick masonry, } \\
\text { stone, or blocks in cement or mixed mortar (no seismic design) - } \\
\text { precast concrete floors. 1-2 stories. }\end{array}$ & KY-1.5 \\
\hline & & & & KY-1.6 \\
\hline & \multirow[t]{2}{*}{1,3} & & confined masonry. 1-5 stories. & KY-1.1 \\
\hline & & & & $\mathrm{KY}-1.2$ \\
\hline & 1,4 & & masonry with seismic provisions (e.g. seismic belts). 1-3 stories. & KY-1.3 \\
\hline \multirow[t]{4}{*}{ EMCA-2 } & 2,1 & \multirow[t]{4}{*}{$\begin{array}{l}\text { monolithic reinforced } \\
\text { concrete buildings }\end{array}$} & buildings with monolithic concrete moment frames. 3-7 stories. & KY-2.1 \\
\hline & 2,2 & & $\begin{array}{l}\text { buildings with monolithic concrete frame } \\
\text { and shear walls (dual system) }\end{array}$ & KY-2.2 \\
\hline & 2,3 & & $\begin{array}{l}\text { buildings with monolithic concrete frames } \\
\text { and brick infill walls. } 2-4 \text { stories. }\end{array}$ & KY-2.3 \\
\hline & 2,4 & & buildings with monolithic reinforced concrete walls. 8-16 stories. & KY-4 \\
\hline \multirow[t]{4}{*}{ EMCA-3 } & 3,1 & \multirow[t]{4}{*}{$\begin{array}{l}\text { precast concrete } \\
\text { buildings }\end{array}$} & $\begin{array}{l}\text { precast concrete large panel buildings } \\
\text { with monolithic panel joints - Seria } 105.1-16 \text { stories. }\end{array}$ & KY-3.1 \\
\hline & 3,2 & & $\begin{array}{l}\text { precast concrete large panel buildings with panel connections } \\
\text { achieved by welding of embedment plates - Seria } 464\end{array}$ & KY-3.2 \\
\hline & 3,3 & & $\begin{array}{c}\text { precast concrete flat slab buildings (consisting of columns } \\
\text { and slabs) - Seria KUB. 5-9 stories. }\end{array}$ & KY-2.8 \\
\hline & 3,4 & & $\begin{array}{c}\text { prefabricated R C frame with linear elements with welded joints } \\
\text { in the zone of maximum loads or with rigid walls in one direc- } \\
\text { tion - Seria 111.IIS04. 6-7 stories. }\end{array}$ & \\
\hline EMCA-4 & 4,1 & $\begin{array}{l}\text { non-engineered } \\
\text { earthen buildings }\end{array}$ & buildings with adobe or earthen walls. 1 story. & KY-9.5 \\
\hline \multirow[t]{2}{*}{ EMCA-5 } & 5,1 & wooden buildings & buildings with load-bearing braced wooden frames. 1-2 stories. & KY-9.7 \\
\hline & 5,2 & & building with a wooden frame and mud infill. 1-2 stories. & KY-9.6 \\
\hline EMCA-6 & 6 & steel buildings & & KY-8 \\
\hline
\end{tabular}

Table 1. The EMCA building typology for Central Asia. An example for Kyrgyzstan (KY) is provided that shows the link of the EMCA building types to the national building typologies (Country code).

details can be found in Wieland et al. [2015].

Prior distributions of the EMCA building types have been derived for the different Central Asian countries based on local expert judgment. The expected compositions have been estimated at the levels of the main building types and the subtypes. Different models are derived for urban and rural areas and are spatially referenced through combination with settlement locations derived from OpenStreetMap and Geonames.

2.2. L2 exposure estimation from satellite images at neighborhood scale

At L2 free of cost medium-resolution multi-spectral satellite images are used to extract the settlement ex- tents and to delineate selected urban areas into zones that appear relatively homogeneous in terms of their predominant building types and approximate construction date period. The resulting zonation at the neighborhood scale ranges from one to several blocks and provides a meaningful aggregation of the exposed building stock information based on physical factors.

An analysis of high-resolution multi-spectral satellite images can further enrich the content of the zones by providing information about the exposed buildings stock, such as location, shape, size and number of buildings. Combination with information from census reports allows, moreover, for a detailed disaggregation and estimation of population numbers to the finer geo- 
cells of the zonation from satellite images. The image processing and analysis steps as well as disaggregation of census data are explained in Wieland et al. [2012b]. Complementary information about parameter tuning and training of image analysis algorithms along with a performance evaluation of different machine learning classifiers that were used for the urban pattern recognition is given in Wieland and Pittore [2014].

\subsection{L3 in-situ data capturing at per-building scale}

The L2 zonation of urban areas is used as input for a stratified sampling procedure to identify areas to be analyzed in greater detail at L3 using in-situ screening techniques [Wieland et al. 2012a]. At this scale, any information is defined at the most detailed level of individual buildings. The sampling strategy combines the zonation with a one dimensional street network of the same area. A route is calculated along the network where a buffer around the streets is taken into account for sample area definition. From each unit of each stratum of the zonation only the buildings that are actually visible from the street are sampled. It is therefore designed for in-situ surveys that aim at capturing characteristics of buildings by mobile mapping systems or by standard Rapid Visual Screening (RVS) techniques [FEMA 154, 2002].

In EMCA several in-situ data capturing techniques are deployed. Available data from previous RVS surveys by local partner institutions were collected, digitized, geocoded and translated into the GEM taxonomy. To cover crucial data gaps, a specific mobile mapping system based on omnidirectional imaging has been developed and deployed to capture images of the buildings along pre-calculated sample routes in selected urban and rural areas. The images are analyzed in the office using a Remote Rapid Visual Screening (RRVS) tool that combines a GIS interface with an omnidirectional image viewer. Details about the mobile mapping system and the RRVS tool and technique can be found in [Wieland et al. 2012c]. Additionally the direct observation tools from the GEM Inventory Data Capture Tools (IDCT) project were used to further fill data gaps. The IDCT direct observation tools come as application for hand-held devices such as mobile phones or tablet PCs. Details can be found in Bevington et al. [2012].

\subsection{Multi-resolution exposure database}

A multi-resolution spatio-temporal database model has been designed in order to hold the exposure data. The database model stores the data at the multiple spatial scales and supports temporal dimensions in order to document changes to exposed assets in space and time. Exposure characteristics are described in the data- base by the GEM building taxonomy [Brzev et al. 2012] which has been implemented in the database model. More details are provided in Wieland et al. [2015].

\subsection{Information integration and rapid vulnerability as-} sessment

Since we are dealing with unevenly distributed information extracted from different sources, at multiple scales with varying accuracies, we decided for a Bayesian approach to information integration and vulnerability assessment. For each building successfully characterized by in-situ or satellite image analysis, the posterior probability distribution of its building type and physical vulnerability can be derived by using Bayesian networks. An exemplification of a simple Bayesian network that combines priors from satellite (construction date period, predominant building type of a zone) and in-situ imaging (building height) with a building typology from the World Housing Encyclopedia (WHE) to derive a posterior probability distribution of the vulnerability classes in terms of the European Macroseismic Scale 1998 (EMS-98) [Grünthal et al. 1998] is given in Pittore and Wieland [2013]. In this case, all information about seismic vulnerability is extracted from the WHE reports. Once vulnerability curves have been compiled for each of the EMCA building types, a more comprehensive Bayesian network will be designed that links the different exposure data sources with the EMCA building types and their respective vulnerability class distributions.

\section{Results}

In the following, results are presented for the different levels. The exposure model is constantly evolving and new data is still being integrated. Due to the dynamic nature of the exposure model in terms of real-world changes (e.g., urban sprawl) and changes related to data availability, the results should be regarded as a snapshot of the current state of an evolving exposure model.

At L1 more than 10,000 settlement locations have been collected along with information about their approximate population, name and indication whether they are urban or rural. The classification into urban or rural has been carried out solely based on the number of inhabitants, meaning that all settlements with 50,000 inhabitants and more have been considered urban. Capital cities have been considered as separate settlement type, since they often show a different composition of building types with respect to the rest of a country. Figure 2 shows a summary of typical EMCA building type distributions for urban and rural areas in the different Central Asian countries. According to the local experts, in urban areas on average over all countries, EMCA-1 
EMCA building types distribution (Urban)

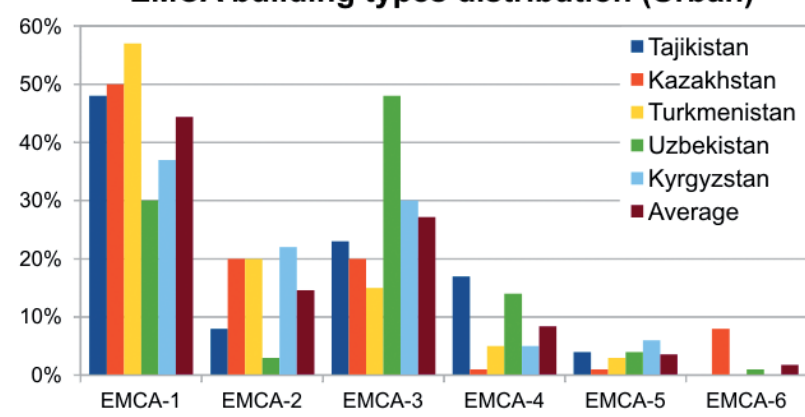

EMCA building types distribution (Rural)

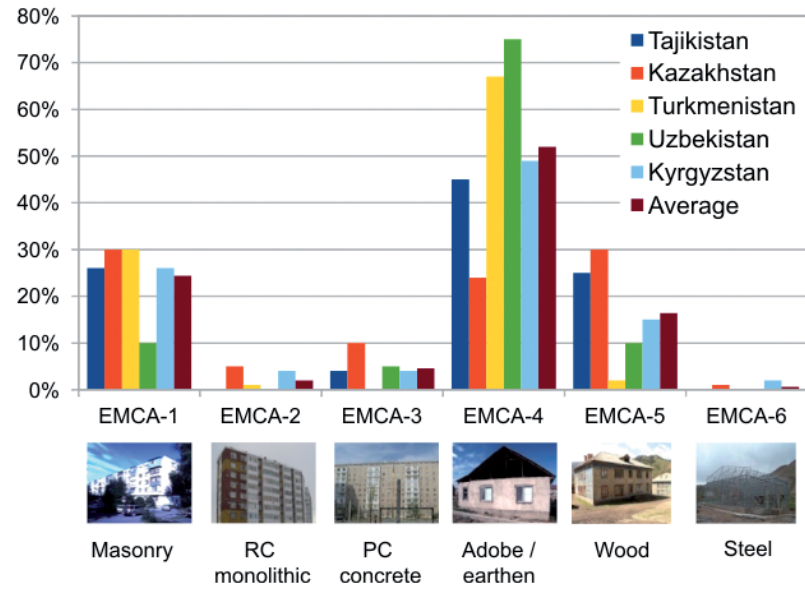

Figure 2. EMCA building type distributions for (a) urban and (b) rural areas in the different Central Asian countries.

multi-story masonry constructions are clearly the dominating building types ( $45 \%$ ), followed by pre-cast concrete structures of EMCA-3 types (28\%). Reinforced concrete monolithic constructions of EMCA-2 types $(15 \%)$ and EMCA-4 adobe / earthen (9\%) constructions compose the remaining building stock, whereas EMCA5 wooden $(2 \%)$ and EMCA- 6 steel (1\%) constructions are rarely present. Only in Kazakhstan the EMCA-6 steel construction types have a slightly higher dominance than in the other Central Asian countries. Rural areas show clearly diverging building type distributions from urban areas, with not-engineered EMCA-4 adobe / earthen building types taking over $50 \%$ of the building stock in average over all Central Asian countries. Masonry (EMCA-1) and wooden (EMCA-5) building types are also present to a large amount, especially in Tajikistan and Kazakhstan. The engineered construction types, like reinforced monolithic (EMCA-2), precast concrete (EMCA-3) and steel (EMCA-6) can hardly be found in rural areas.

At L2 the up-to-date settlement extents have been extracted from Landsat 8 satellite imagery of the year 2013 (Figure 1). For capital cities and selected urban areas, a further zonation has been derived from the imagery in terms of the distribution of areas with predominant building types and approximate construction date periods. The zonation has been enriched with in- formation about the number, location and shape of single buildings derived from high-resolution satellite images of the Quickbird and WorldView-2 sensors. Together with information from local census reports, a refined distribution of the urban population could be disaggregated [Wieland et al. 2012b]. Figure 3 shows the example of Dushanbe, the capital of Tajikistan. For the main urban area of Dushanbe, a total of 85,442 buildings with a combined population of 861,334 people have been estimated. Despite a clear dominance of "1-3 storey buildings", the population estimation indicates an equal distribution of inhabitants between this building type (29\%), "2-4 storey and 4-16 storey buildings" (34\%) and "mixed built-up areas" (37\%). In combination with the outcomes of a change detection analysis, it becomes clear that most of the newly builtup areas (96\% of the buildings built between 1989 and 2010) consist of "1-3 storey buildings". In 1972, a total area of $54 \mathrm{~km}^{2}$ (28,812 buildings) was classified as being built-up in greater Dushanbe. In 1989, the built environment in Dushanbe and its surroundings accounted for $121 \mathrm{~km}^{2}$ (57,412 buildings), while in 2010 the city reached a total built-up area of $185 \mathrm{~km}^{2}(84,442$ buildings). The urban sprawl between 1972 and 1989 concentrated mainly in the North-South direction in the areas along the Varzob River and in the northern and eastern parts of the city facing the mountain slopes. Between 1989 and 2010, Dushanbe expanded rapidly mainly in southern direction and towards the steeper slopes of the fringing mountain ranges in the NorthEast. The areas along the bottom of the mountain slopes are particularly prone to soil-liquefaction and the steeper slope parts show a large potential for (possibly earthquake-triggered) landslides [Havenith et al. 2003].

At L3 available data about single buildings have been collected for selected settlements. In Dushanbe the Institute for Geology, Earthquake Engineering and Seismology (IGEES) has collected data about more than 3,000 buildings through in-situ screening (Figure 4). The data acquisition was carried out over several years in previous projects and within EMCA the data were digitized, translated and transformed into the GEM Building Taxonomy. Moreover, the previously assigned address geocoding was transformed into a coordinate-based geocoding to allow for robust and rapid spatial data queries. After pre-processing of the data it became clear that they are clustered concerning the locations and the building types that were surveyed. Especially, the areas constructed after the 1990s with mainly private singleunit buildings were largely missing. In order to produce a per-building dataset that can be regarded as being representative for the current building stock of Dushanbe, an in-situ omnidirectional image acquisition campaign 

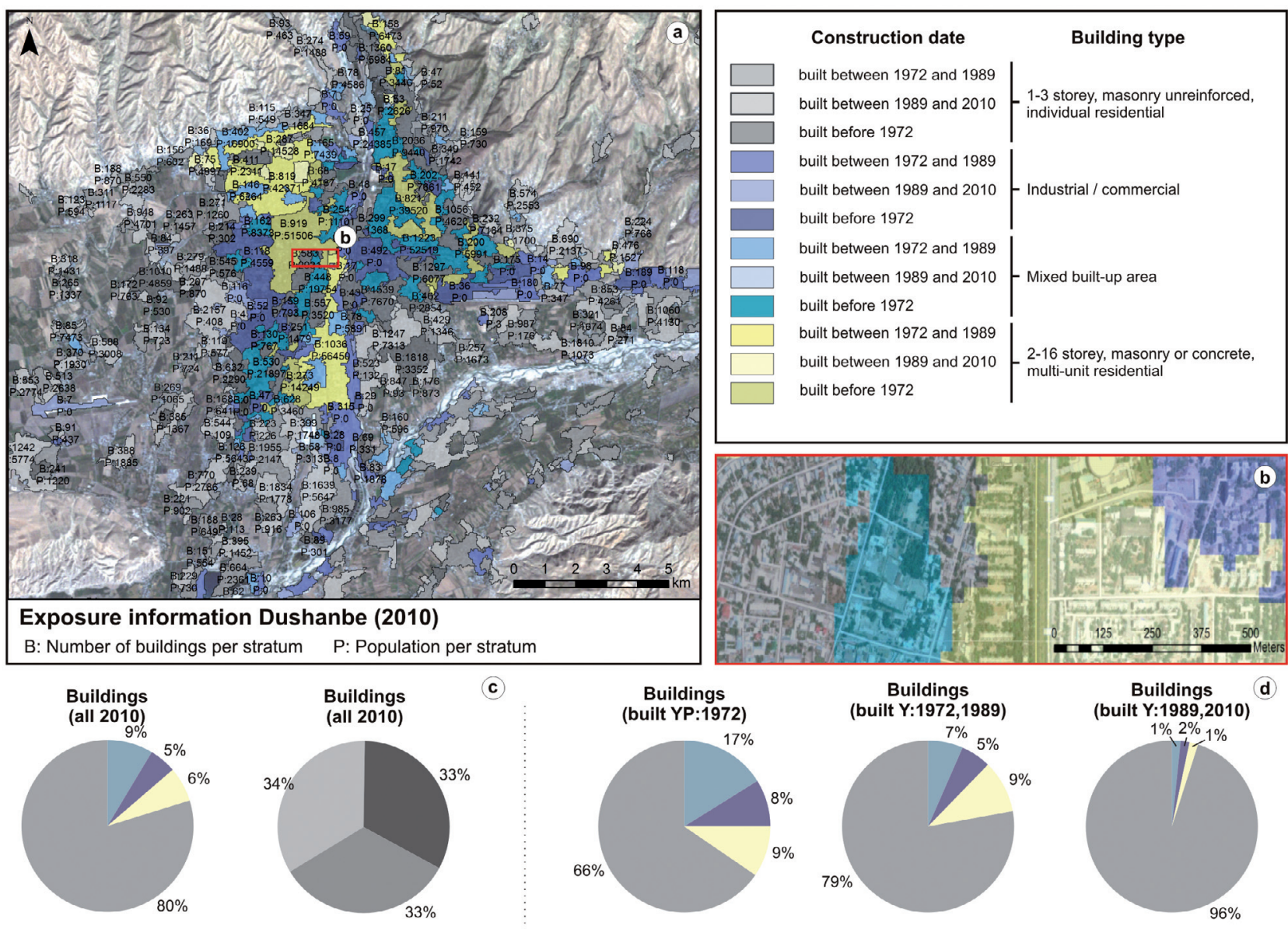

(c)

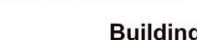

\section{然}

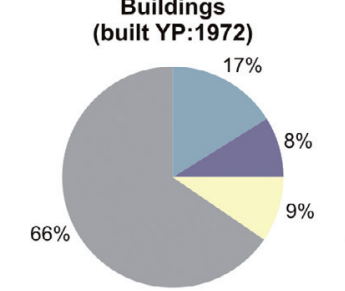

Buildings

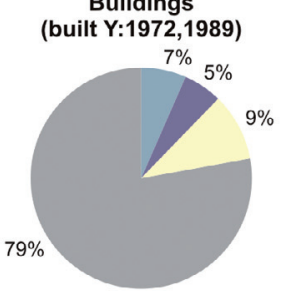

Buildings c
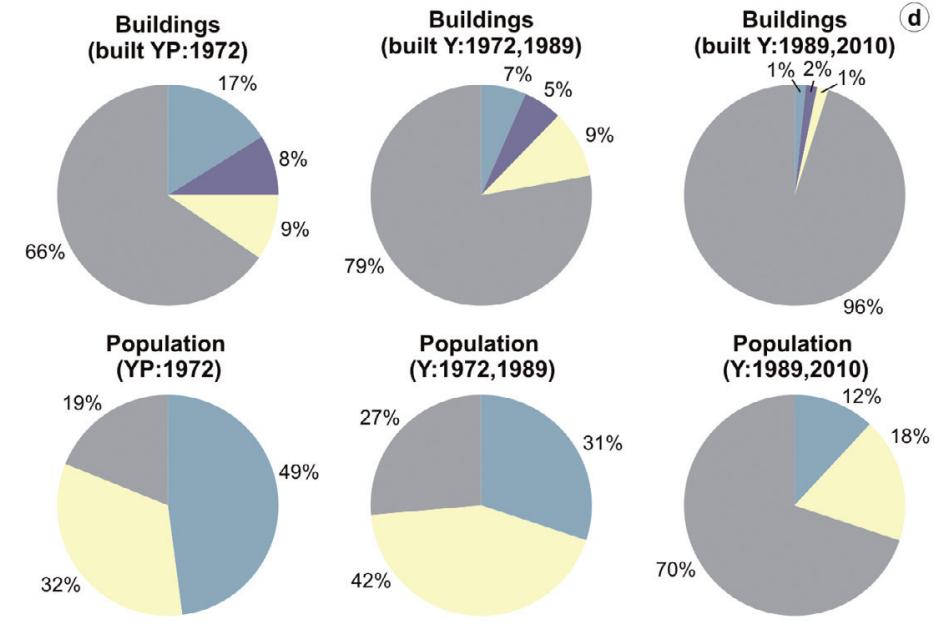

Population

(Y:1989,2010)
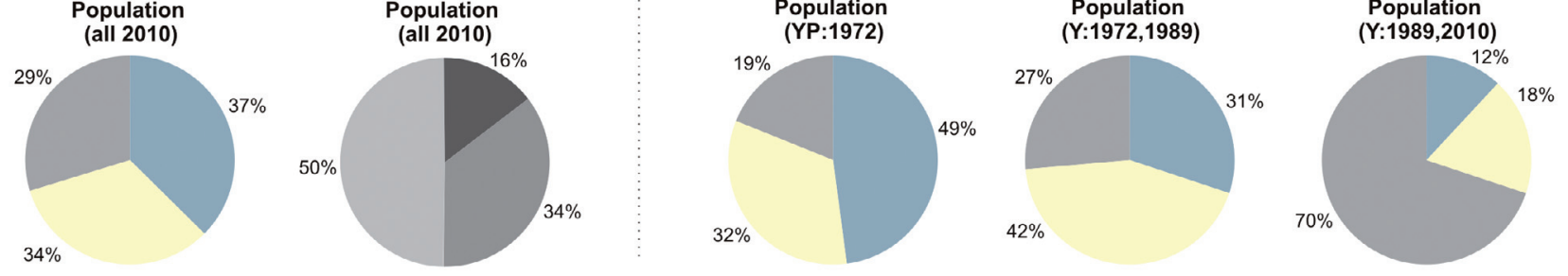

YP:1972 $\square$ Y:1989,2010
$\square: 1972,1989$

1-3 storey, masonry unreinforced, individual residential

2-16 storey, masonry or concrete, multi-unit residential

Industrial / commercial

Mixed built-up

Figure 3. L2 exposure zonation from satellite images for Dushanbe, the capital of Tajikistan, with (a) Building type distribution and distribution of areas with similar construction date period. (b) Magnified view of the L2 exposure zonation extracted from medium-resolution satellite images and superimposed on a high-resolution image. (c) Composition of the number of buildings and the population per building type and per construction date period in Dushanbe in 2010. (d) Composition of the number of buildings and population per building types grouped by construction date period.

was carried out. The L2 exposure zonation from satellite images together with a vectorial street network of the city and the distribution of previously collected data was used as input to plan the survey beforehand and to calculate sample routes to be covered during the survey. Within 5 days of data acquisition, more than 1,000,000 omnidirectional images have been acquired. The images are being analyzed offline by researchers of the IGEES using the RRVS desktop system. So far 1,000 additional buildings have been screened in this manner and detailed structural and non-structural characteristics could be extracted, such as material type, lateral load resisting system, height, occupancy, etc. Other settlements for which per-building data are being inte- grated include Bishkek, Osh, Jalalabad and settlements in the Batken province in Kyrgyzstan; Khorog and settlements in the Jirgatal province in Tajikistan; Almaty in Kazakhstan.

\section{Discussion and conclusions}

This paper provided an overview of the development efforts to compose a cross-border exposure model for Central Asia. Main challenges that have been tackled include a general lack of up-to-date exposure data in Central Asia at all analysis scales and cross-border heterogeneity of available data in terms of description, classification, quality, spatial coverage and level of detail. New data collection tools and techniques were developed; 


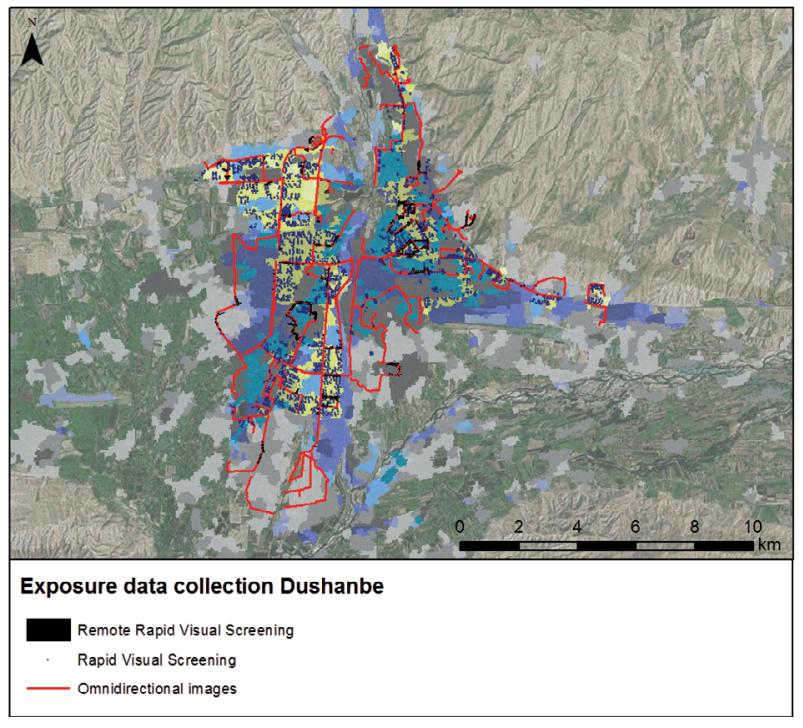

Figure 4. Exposure data collected at L3 for the city of Dushanbe, Tajikistan.

concepts for efficient exposure data management, harmonization and integration were provided and tested as part of the EMCA exposure model activities.

A major step towards a cross-border harmonization of risk assessment could be achieved through the development of a harmonized building typology for Central Asia as results of collaborative efforts by experts from all the relevant countries. The development of vulnerability curves for the different EMCA building types, however, still remains an open topic to be tackled in the next phases. Bayesian networks could provide a flexible and transparent technique for information integration and first rapid vulnerability estimation under consideration of uncertainties [Pittore and Wieland 2013]. More research in the direction of probabilistic information integration is currently undertaken. The use of remote sensing coupled with novel in-situ data capturing and analysis tools could further enhance the efficiency of perbuilding data acquisition. Due to the pyramidal structure of the approach, the geographical analysis focus could be narrowed and cost- and time-resources could be minimized through the use of sampling strategies.

Especially in seismic risk assessment the significant dynamics are largely introduced by changes to the exposed assets and their vulnerability. Therefore, the development of an exposure model should be regarded as a continuous process where data is iteratively collected, information is integrated and a model is updated under consideration of the spatial distribution of the model uncertainties, the obsoleteness of available information and the evolution of the exposed environment. In Central Asia this becomes particularly important due to an increasingly high spatio-temporal variability and concentration of exposed assets in hazardous areas that can be observed in recent years.
Acknowledgements. The research presented within this article has been supported by EMCA (Earthquake Model Central Asia), Helmholtz EOS (Earth Observation System), PROGRESS (Georisiken im Globalen Wandel) and SENSUM (Grant agreement no: 312972). The authors would like to thank the editors and the anonymous reviewers for suggestions which helped to improve this paper and Dr. K. Fleming for English language revision. The authors also would like to thank their Central Asian colleagues for their great support, contribution and warm hospitality.

\section{References}

Bevington, J., R. Eguchi, C. Huyck et al. (2012). Exposure Data Development for the Global Earthquake Model: Inventory Data Capture Tools, Proceedings of the 15th World Conference on Earthquake Engineering.

Brzev, S., C. Scawthorn, A.W. Charleson and K. Jaiswal (2012). Interim Overview of GEM Building Taxonomy V2.0, Report produced in the context of the GEM Building Taxonomy Global Component.

FEMA 154 (2002). Rapid visual screening of buildings for potential seismic hazards: a handbook, 2nd ed. ATC, Washington D.C.

Giardini, D., G. Grünthal, K. Shedlock and P. Zhang (1999). The GSHAP Global Seismic Hazard Map, Annali di Geofisica, 42 (6), 1225-1230.

Grünthal, G., R.M.W. Musson, J. Schwarz and M. Stucchi (1998). European Macroseismic Scale 1998 (EMS-98), European Seismological Commission.

Havenith, H.B., A. Strom, D. Jongmans, A. Abdrakhmatov, D. Delvaux and P. Tréfois (2003). Seismic triggering of landslides, Part A: Field evidence from the Northern Tien Shan, Natural Hazards and Earth System Science, 3, 135-149.

King, S., V. Khalturin and B. Tucker (1999). Seismic Hazard and Building Vulnerability in Post-Soviet Central Asian Republics, Proceedings of the NATO Advanced Research Workshop on Earthquake Risk Management Strategies for Post-Soviet Central Asian Republics: Avoiding Repetition of 1988 a Shakhalin Disasters, Almaty, Kazakhstan, 22-25 October 1996. Kluwer, Dordrecht.

Pittore, M., and M. Wieland (2013). Toward a rapid probabilistic seismic vulnerability assessment using satellite and ground-based remote sensing, Natural Hazards, 68 (1), 115-145; doi:10.1007/s11069-0120475-z.

Ullah, S., D. Bindi, M. Pilz, L. Danciu, G. Weatherill, E. Zuccolo, A. Ischuk, N.N. Mikhailov, K. Abdrakhmatov and S. Parolai (2015a). Probabilistic seismic hazard assessment for Central Asia, Annals of Geophysics, 58 (1), S0103; doi:10.4401/ag-6687.

Ullah, S., D. Bindi, M. Pilz and S. Parolai (2015b). Probabilistic seismic hazard assessment of Bishkek, Kyrgyzstan, considering empirically estimated site effects, 
Annals of Geophysics, Annals of Geophysics, 58 (1), S0105; doi:10.4401/ag-6682.

Wieland, M., M. Pittore, S. Parolai et al. (2012a). Estimating building inventory for rapid seismic vulnerability assessment: Towards an integrated approach based on multi-source imaging, Soil Dynamics and Earthquake Engineering, 36, 70-83; doi:10.1016/j.soil dyn.2012.01.003.

Wieland, M., M. Pittore, S. Parolai and J. Zschau (2012b). Exposure Estimation from Multi-Resolution Optical Satellite Imagery for Seismic Risk Assessment, ISPRS International Journal of Geo-Information, 1, 69-88; doi:10.3390/ijgi1010069.

Wieland, M., M. Pittore, S. Parolai and J. Zschau (2012c). Remote sensing and omnidirectional imaging for efficient building inventory data-capturing: Application within the Earthquake Model Central Asia, Geoscience and Remote Sensing Symposium (IGARSS), 2012 IEEE International, 3010-3013.

Wieland, M., and M. Pittore (2014). Performance evaluation of machine learning algorithms for urban pattern recognition, Remote Sensing, 6, 2912-2939.

Wieland, M., M. Pittore, S. Parolai et al. (2015). A multiscale exposure model for seismic risk assessment in Central Asia, Seismological Research Letters, 86, 113; doi:10.1785/0220140130.

*Corresponding author: Marc Wieland,

Helmholtz Center Potsdam - German Research Center for Geosciences, Potsdam, Germany; email: mwieland@gfz-potsdam.de.

C) 2015 by the Istituto Nazionale di Geofisica e Vulcanologia. All rights reserved. 